\title{
DETEKSI ALAT PELINDUNG KEPALA (HELM) MENGGUNAKAN METODE HAAR CASCADE CLASSIFIER
}

\author{
Sugianto $^{1}$, Endang Setyati ${ }^{2}$, Hendrawan Armanto ${ }^{3}$ \\ ${ }^{1}$ Teknik Informatika, Universitas Islam Majapahit \\ ,2,3 Teknologi Informasi, Sekolah Tinggi Teknik Surabaya \\ ${ }^{1}$ Sugik2007@yahoo.com
}

\begin{abstract}
ABSTRAK
Penggunaan alat pelindung kepala helm seringkali dianggap tidak penting dan remeh oleh pekerja. Padahal penggunaan alat pelindung kepala helm ini sangat penting dan berpengaruh terhadap keselamatan dan kesehatan kerja pekerja. Kedisiplina para pekerja dalam menggunakan alat pelindung kepala tergolong masih rendah sehingga resiko terjadinya kecelakaan kerja yang dapat membahayakan pekerja cukup besar. Dalam penelitian ini bertujuan untuk mendeteksi alat pelindung kepala helm pada video. Pada penelitian ini metode yang digunakan adalah Haar Cascade Classifier. Sistem terdiri dari dua proses utama yaitu proses training data dan proses deteksi. Proses training metode ini mempunyai empat proses utama yaitu, haar-like feature, citra integral, ada-boost dan cascade classifier. Haar-like feature merupakan kumpulan fitur khusus yang mempresentasikan kepala,wajah dan helm. Citra integral adalah cara cepat menghitung haar feature. Sedangkan ada-boost adalah pembobotan secara statistik nilai-nilai fitur yang didapat dan di-filter mengunakan cascade classifier. Proses deteksi dalam penelitian ini ada dua proses, yang pertama proses deteksi apakah manusia atau bukan, jika hasil yang dideteksi manusia akan dilanjutkan proses deteksi apakah menggunakan helm atau tidak. Pengujian sistem pendeteksi dilakukan secara individu dengan menggunakan warna helm merah, biru dan kuning diperoleh tingkat keakuratan sebesar 92\%, sedangkan pengujian secara kelompok diperoleh tingkat keakuratan sebesar 71 $\%$.
\end{abstract}

Kata kunci: Alat pelindung kepala, deteksi helm, Haar Cascade Classifier.

\begin{abstract}
Use of protective gear helmet head is often considered unimportant and trivial by workers. Whereas the use of protective headgear helmet is very important and affect the safety and health of workers. Kedisiplina workers to use protective gear head is still low so that the risk of accidents that could endanger workers large enough. In this research aims to detect protective equipment head helmet on video. In this study, the method used is the Haar Cascade Classifier. The system consists of two main processes, namely the process of training data and the detection process. This method of training process has four main processes, haar-like feature, integral image, no-boost and cascade classifier. Haar-like feature is a collection of special features presented the head, face and helmet. Citra is how to quickly calculate integrals haar feature. While no-boost are statistically weighted feature values are obtained and filtered using a cascade classifier. The detection process in this study there are two processes, the first detection process whether human or not, if the result of human detected will continue the process of detection of whether to use a helmet or not. Detection system testing is done individually using helmet colors red, blue and yellow. It obtained accuracy rate of 92\%, while the testing group obtained the degree of accuracy of $71 \%$.
\end{abstract}

Keywords : head protective equipment, detection helmets, Haar Cascade Classifier. 


\section{PENDAHULUAN}

\subsection{Latarbelakang}

Kecelakaan kerja dapat terjadi sewaktu-waktu dan dapat menimpa siapa pun, sedangkan tingkat kesadaran pekerja menggunakan alat pelindung kepala masih kurang dan masih menggangap remeh fungsinya sehingga resiko terjadinya kecelakaan kerja cukup besar. Oleh karena itu diperlukan suatu sistem yang digunakan untuk mendeksi dan mengetahui pekerja menggunakan alat pelindung kepala helm. Sehingga dapat dilakukan pencegahan dan meminimalkan terjadinya kecelakaan kerja akibat tidak disiplinya pekerja dalam pemakaian alat pelindung kepala, disini peneliti mencoba membuat sistem dekteksi Alat Pelindung Kepala helm di PT Trias.

Pada penelitian ini menggunakan metode Haar Cascade Classifier, metode ini memiliki kecepatan dan keakurantan yang tinggi karena menggabungkan beberapa konsep (Haar Feature, Integral Image, AdaBoost, dan Cascade Classifier) menjadi sebuah metode utama untuk mendeteksi obyek alat pelindung kepala helm. Hasil akhir yang ingin didapatkan adalah sistem mampu mendeteksi apakah pekerja menggunakan alat pelindung kepala helm atau tidak. Adapun data yang diolah dalam penelitian ini adalah video rekaman pekerja ketika memasuki area produksi.

\subsection{Referensi \\ Cascade Classifier}

Berikut ini merupakan tahapan proses mengunakan algoritma cascade classifier ada empat tahapan:

1. Fitur Haar [6].

Fitur haar-like merupakan fitur sederhana berbentuk kotak ydimana fitur ini menggunakan menggunakan haar-like features yang perlu dilakukan training terlebih dahulu untuk mendapatkan suatu pohon keputusan dengan nama cascade classifier sebagai penentu apakah ada obyek atau tidak dalam tiap frame yang di proses.

Haar Feature adalah fitur yang didasarkan pada Wavelet Haar (Viola, Paul and Michael Jones, 2001). Wavelet Haar adalah gelombang tunggal bujur sangkar (satu interval tinggi dan satu interval rendah). Untuk dua dimensi, satu terang dan satu gelap. Selanjutnya kombinasi-kombinasi kotak yang digunakan untuk pendeteksian objek visual yang lebih baik. Setiap Haarlike feature terdiri dari gabungan kotak-kotak hitam dan putih.
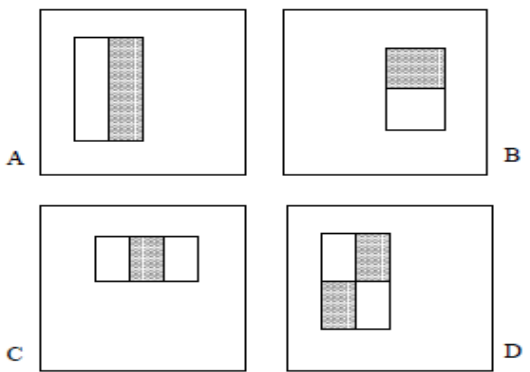

Gambar 1.Haar Feature
Untuk mempercepat perhitungan Haar-like feature [6] dapat menggunakan teknik citra integral seperti Gambar 1 .

3 tipe kotak (rectangular) feature :

- A dan B Tipe two-rectangle feature (horisontal/vertikal).

- C adalah Tipe three-rectangle feature.

- D adalah Tipe four-rectangle feature.

Adanya fitur Haar ditentukan dengan cara mengurangi rata-rata piksel pada daerah gelap dari ratarata piksel pada daerah terang. Jika nilai perbedaannya itu diatas nilai ambang atau treshold, maka dapat dikatakan bahwa fitur tersebut ada. Nilai dari Haar-like feature adalah perbedaan antara jumlah nilai-nilai piksel gray level dalam daerah kotak hitam dan daerah kotak putih. Untuk kotak pada Haar-like feature dapat dihitung secara cepat menggunakan "integral image".

\section{Integral image.}

Integral Image digunakan untuk menentukan ada atau tidaknya dari ratusan fitur Haar pada sebuah gambar dan pada skala yang berbeda secara efisien. Pada umumnya, pengintegrasian tersebut berarti menambahkan unit-uit kecil secara bersamaan. Dalam hal ini unit-unit kecil tersebut adalah nilai-nilai piksel. Nilai integral untuk masing-masing piksel adalah jumlah dari semua piksel-piksel dari atas sampai bawah.

Integral image adalah representasi tengah (intermediate) untuk suatu citra yang terdiri dari jumlah nilai keabu-abuan (grayscale pixel) dari citra tersebut dengan tinggi y dan lebar x. Integral image pada lokasi $\mathrm{x}, \mathrm{y}$ merupakan jumlah dari pixel-pixel mulai dari atas sampai piksel sebelah kiri dari $\mathrm{x}, \mathrm{y}$. lihat rumus dibawah ini :

$(x, y)=\sum_{x^{\prime}<x, y^{\prime}<y} \mathrm{i}\left(\mathrm{x}^{\prime}, \mathrm{y}^{\prime}\right)$

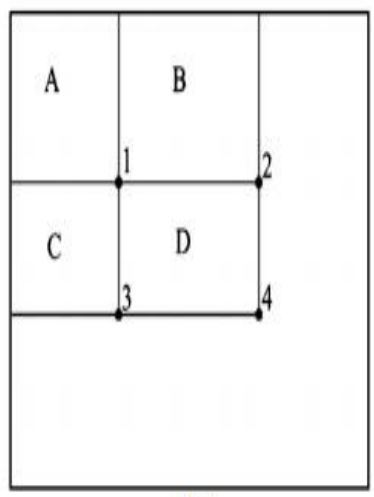

(a)

\begin{tabular}{|c|c|}
\hline Citra Asli & Citra Integral \\
\hline 52341 & 57101415 \\
\hline 15423 & 613202630 \\
\hline 22134 & 817253442 \\
\hline 35645 & 1125395265 \\
\hline 41326 & 1530476281 \\
\hline $\begin{array}{c}5+4+2+ \\
2+1+3=17\end{array}$ & $34 \cdot 14 \cdot 8+5=17$ \\
\hline
\end{tabular}

(b)
Gambar 2. Citra integral. (a) konsep citra integral; (b) penerapan menghitung intensitas citra integral.

Setelah citra integral terbentuk maka jumlah intensitas piksel region kotak pada citra asli dapat dengan mudah dihitung dengan melihat empat titik referensi pada citra integral. Misal ada empat region yang saling bertetangga A, B, C, D dengan masingmasing piksel ujung kanan bawah region tersebut adalah 
1, 2, 3, 4 (Gambar 3.3), maka untuk mencari akumulasi intensitas piksel dari region $\mathrm{D}$ diperoleh dengan cara menghitung piksel-piksel kanan bawah region $\mathrm{D}$ dan tiga region tetangga lainnya pada citra integral yaitu : 4 $-2-3+1$.

\section{Cascade AdaBoost}

Fitur Haar-like menghasilkan jumlah fitur yang sangat besar. Semua fitur diseleksi menggunakan algoritma adaboost. Melalui proses iterasi dan pembobotan citra latih, tiap fitur satu persatu diuji seberapa baik dalam memisahkan sample positif dan negatif.

Training data pada Haar memerlukan 2 tipe gambar objek dalam proses training yang dilakukan, yaitu :

a. Positive samples, Berisi gambar obyek yang ingin di deteksi. Berisi gambar obyek yang ingin di deteksi. Dalam penelitian ini, positive samples merupakan gambar pekerja yang menggunakan alat pelindung kepala berupa helm.

b. Negative samples, Berisi gambar obyek selain obyek yang ingin dideteksi (gambar pekerja yang menggunakan alat pelindung kepala berupa helm). Dalam penelitian ini, negative samples merupakan gambar umumnya berupa gambar background (tembok, pemandangan, lantai, pekerja yang tidak memakai helm dan gambar lainnya). Resolusi untuk sampel negatif disarankan untuk memiliki resolusi yang sama dengan resolusi kamera.

Informasi dari hasil training ini lalu dikonversi menjadi sebuah parameter model statistik. Deteksi obyek mempekerjakan varian dari AdaBoost algoritma untuk pembelajaran atau machine learning memilih fitur yang terbaik dan untuk melatih pengklasifikasi yang menggunakannya algoritma ini membangun sebuah classifier kuat sebagai kombinasi dari pengklasifikasi yang lemah.

4. Pengklasifikasi bertingkat (Cascade Classifier).

Cascade classifier adalah sebuah rantai stage classifier, dimana setiap stage classifier digunakan untuk mendeteksi apakah di dalam image sub window terdapat obyek yang diinginkan (object of interest). Stage classifier dibangun dengan menggunakan algoritma adaptive-bosst (Adaboost). Algoritma tersebut mengkombinasikan performansi banyak weak classifier untuk menghasilkan strong classifier. Weak classifier dalam hal ini adalah nilai dari haar-like feature. Jenis Adaboost yang digunakan adalah Gentle Adaboost.

\section{HASIL DAN PEMBAHASAN}

\subsection{Arsitektur Sistem}

Secara umum sistem yang dibangun mempunyai struktur yang ditunjukan pada Gambar 3.

\subsubsection{Training}

Pada proses training ini menggunakan data gambar negatif sebanyak 1627 dan data gambar positif sebanyak 1026, dengan parameter detection rate $=1$ dan maxFalseAlarm rate $=0,5$ dengan jumlah tingkat cascade adaboost $=20$, mode ALL sedangkan ukuran obyek manusia memiliki lebar 40 pixel dan tinggi 30 pixel.

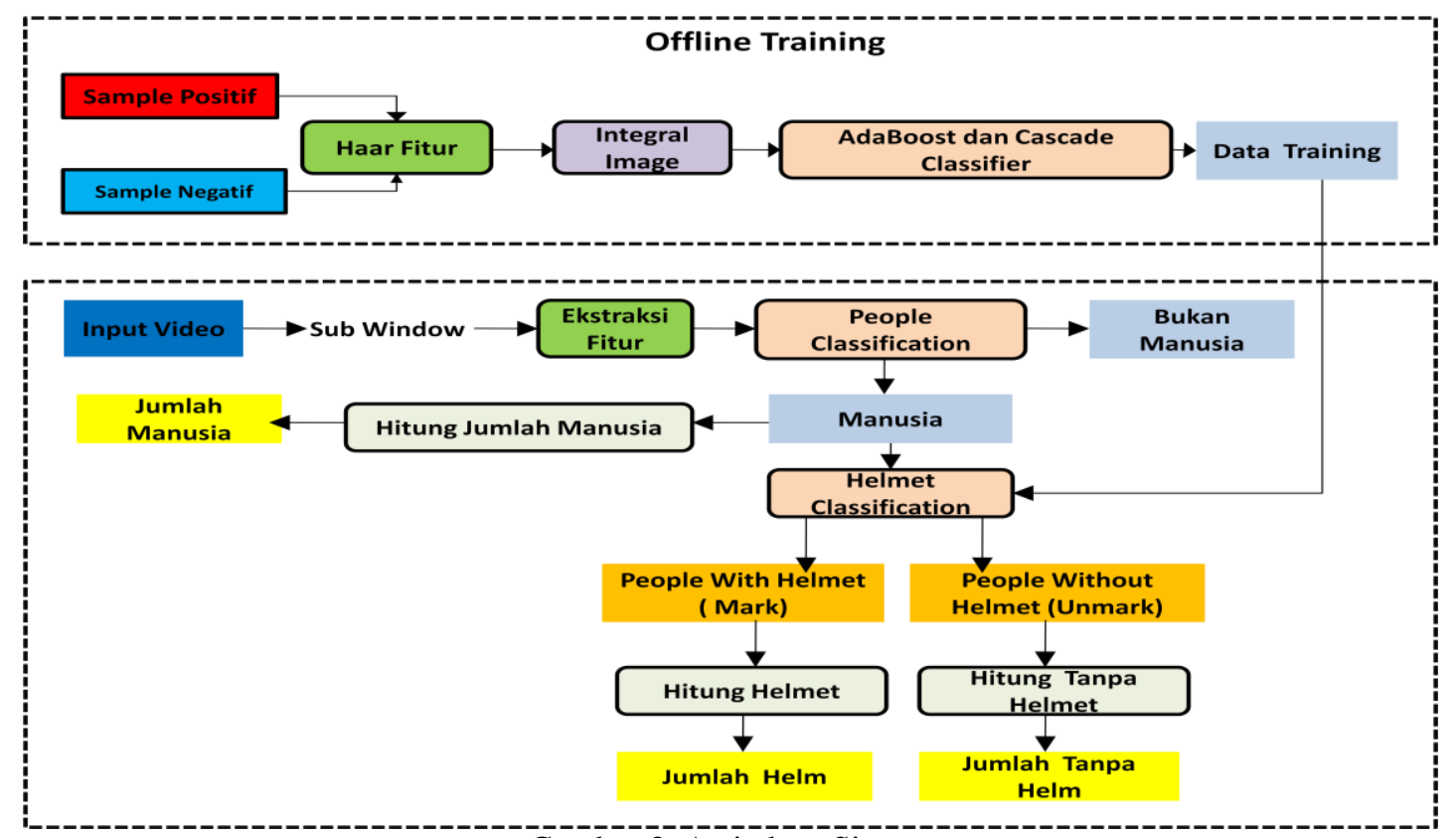

Gambar 3. Arsitektur Sistem 

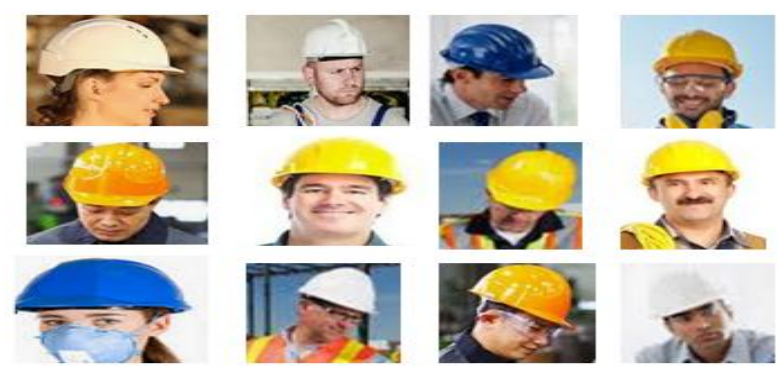

Gambar 4. Data Sampel Positif
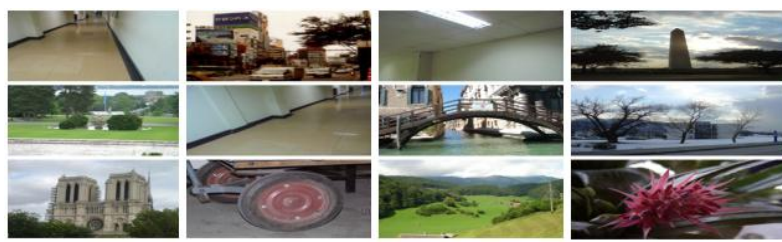

Gambar 5. Data Sampel Negatif

\subsection{Hasil Uji Coba}

Berikut beberapa hasil uji coba yang dilakukan pada penelitian ini untuk proses deteksi pada video pekerja sebanyak 20 frame ketika memasuki area produksi.

Pada Gambar 6 untuk hasil uji coba 1, kondisi pekerja berjumlah satu orang dengan menggunakan helm warna merah, sistem berhasil mendeteksi dengan benar beserta penghitungan yaitu jumlah people 1 orang, jumlah yang menggunakan helm 1 orang dan jumlah yang tidak menggunaan helm 1 orang. Pada gambar 7 untuk hasil uji coba 2, menunjukkan kondisi yang berbeda yaitu jumlah pekerja sebanyak dua orang saling sejajar. Ini menjadi tantangan tersendiri untuk proses deteksi karena objek yang bergerak sangat cepat. Pada hasil uji coba ini, sistem dapat mendeteksi dengan benar untuk orang yang sebelah kiri yang menggunakan helm warna biru dan untuk orang yang sebelah kanan dalam kondisi tidak menggunakan helm.

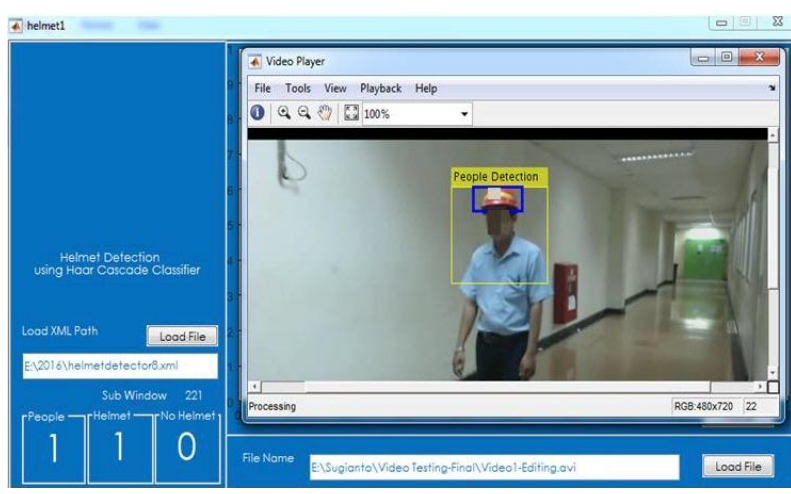

Gambar 6. Hasil Uji Coba 1

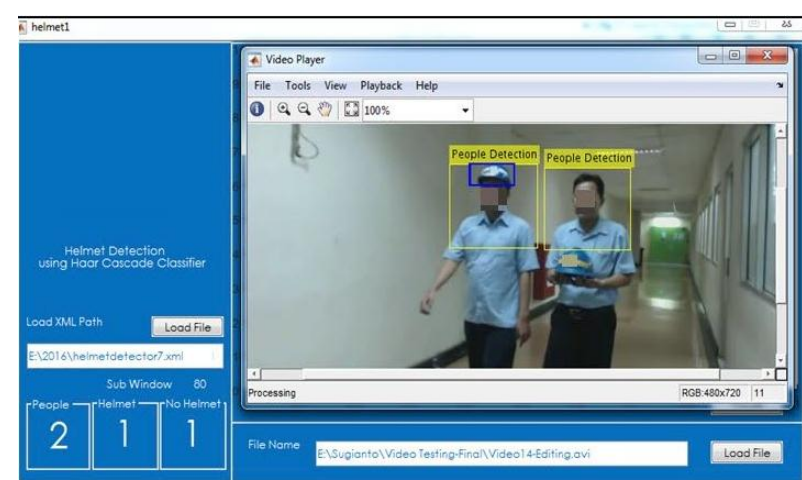

Gambar 7. Hasil Uji Coba 2

Tabel 1 dibawah ini merupakan ringkasan hasil uji coba yang dilakukan dengan mengkondisikan pekerja sesuai dengan pola kedatangan pekerja (secara individu atau kelompok ataupun pada saat masuk secara berkelompok apakah mereka berjalan sejajar atau berderet dari sebagian di depan dan sebagian di belakang) ketika memasuki area kerja serta kemungkinan tingkah laku mereka ketika membawa helm (digunakan atau ditenteng) serta jenis helm yang dikategorikan berdasarkan warnanya (merah, kuning, hijau).

Tabel 1. Data Hasil Pengujian

\begin{tabular}{|c|c|c|c|c|}
\hline Video & Kondisi & $\begin{array}{c}\text { Precision } \\
(\%)\end{array}$ & $\begin{array}{c}\text { Recall } \\
(\%)\end{array}$ & $\begin{array}{c}\text { F1-Score } \\
(\%)\end{array}$ \\
\hline \multicolumn{7}{|c|}{ Individu } & 100 \\
\hline Vid 1 & Jumlah pekerja 1 orang dan Helm berwarna merah. & 100 & 100 & 85 \\
\hline Vid 2 & Jumlah pekerja 1 orang dan Helm berwarna kuning. & 85 & 85 & 92 \\
\hline Vid 3 & Jumlah pekerja 1 orang dan Helm berwarna biru. & 90 & 95 & 92 \\
\hline \multicolumn{7}{|c|}{ Kelompok } & 92 & 93 & 100 \\
\hline Vid 4 & $\begin{array}{c}\text { Jumlah pekerja 2 orang, tidak menggunakan helm dengan } \\
\text { kondisi helm dibawa dan ditentang tegak lurus. }\end{array}$ & 100 & 100 & 55 \\
\hline Vid 5 & $\begin{array}{c}\text { Jumlah pekerja 2 orang,1 orang menggunakan helm dan 1 } \\
\text { orang tidak dgn kondisi helm ditentang tegak lurus. }\end{array}$ & 52 & 60 & 87 \\
\hline Vid 6 & Jumlah pekerja 2 orang, keduanya menggunakan helm. & 87 & 87 & 40 \\
\hline Vid 7 & $\begin{array}{c}\text { Jumlah pekerja 4 orang, kondisi 2 orang menggunakan } \\
\text { helm dan 2 orang tidak menggunakan helm. }\end{array}$ & 100 & 25 & 71 \\
\hline \multicolumn{7}{|c|}{ Rata-rata } & 85 & 68 & 7 \\
\hline
\end{tabular}




\section{KESIMPULAN}

Dari hasil pengujian pada Tabel 1 terhadap 7 video seo sebanyak 20 frame yang dilakukan diperoleh tingkat akurasi penilaian sebesar $92 \%$ untuk kondisi jumlah pekerja 1 orang dan memakai helm dengan warna merah, kuning dan biru. Sedangkan untuk jumlah pekerja kondisi lebih dari satu memiliki tingkat akurasi sebesar $71 \%$.

\section{PUSTAKA}

Dewiani Djamaluddin, Tantri Indrabulan, Andani, Indrabayu, Siti Wetenriajeng Sidehabi., 2014, "The Simulation of Vehicle Counting System for Traffic Surveillance using viola jones method," Proceedings Conference on Makassar International Conference on Electrical Engineering and Informatics.

Krishna M.G \& Srinivasulu, A., 2012. Face Detection System On AdaBoost Algorithm Using Haar Classifiiers. , Vol. 2, Issue. 5. Sept 2012 pp-35563560 .

http://pc01.lib.ntust.edu.tw/ETD-db/ETDsearch/view_etd?URN=etd-0801114-211844,"

A Cascade Classifier Using the Adaboosting Algorithm for Real-time On-road Motorcycle Detection and Tracking”, 2014.

Mahdi Rezaei,"Creating a Cascade of Haar-Like Classifiers:Step by Step" Departement of computer Science, the university of Auckland, 2014.

D'Souza, D., \& Yampolskiy, R. V., 2010. Avatar Face Detection using an Extended Set of Haar-like Features. [Journal Abstract]. Kentucky Academy of Science, 71(1-2), 108.

P. Viola and M. Jones., 2001. "Robust real-time object detection," International Journal of Computer Vision, 57(2), 137-154.

Aijuan Dong, Athena Johnson, George Dimitoglou, and Joshua Shelley., 2014. " Automatic Solar Cavity Detection Using Haar Cascade Classifier", Conference paper.

http://hitamandbiru.blogspot.co.id/2012/08/makala h-keselamatan-dan-kesehatan-kerja.html.

Mokhtar., 1992. Keselamatan dan Kesehatan Kerja pada pekerja. Bandung: CV Medika. 